\title{
Understanding, beliefs and perspectives of Aboriginal people in Western Australia about cancer and its impact on access to cancer
} services

\author{
Shaouli Shahid*, Lizzie Finn, Dawn Bessarab and Sandra C Thompson
}

Address: Centre for International Health, Curtin University of Technology, GPO Box U1987, Perth WA 6845, Australia

Email: Shaouli Shahid* - s.shahid@curtin.edu.au; Lizzie Finn - l.finn@curtin.edu.au; Dawn Bessarab - d.bessarab@curtin.edu.au; Sandra C Thompson - s.thompson@curtin.edu.au

* Corresponding author

Published: 31 July 2009

BMC Health Services Research 2009, 9:132 doi:10.1 186/1472-6963-9-132

Received: I April 2009

Accepted: 31 July 2009

This article is available from: http://www.biomedcentral.com/1472-6963/9//32

(C) 2009 Shahid et al; licensee BioMed Central Ltd.

This is an Open Access article distributed under the terms of the Creative Commons Attribution License (http://creativecommons.org/licenses/by/2.0), which permits unrestricted use, distribution, and reproduction in any medium, provided the original work is properly cited.

\begin{abstract}
Background: Despite a lower overall incidence, Aboriginal Australians experience poorer outcomes from cancer compared with the non-Aboriginal population as manifested by higher mortality and lower 5year survival rates. Lower participation in screening, later diagnosis of cancer, poor continuity of care, and poorer compliance with treatment are known factors contributing to this poor outcome. Nevertheless, many deficits remain in understanding the underlying reasons, with the recommendation of further exploration of Aboriginal beliefs and perceptions of cancer to help understand their care-seeking behavior. This could assist with planning and delivery of more effective interventions and better services for the Aboriginal population. This research explored Western Australian (WA) Aboriginal peoples' perceptions, beliefs and understanding of cancer.

Methods: A total of 37 Aboriginal people from various geographical areas within WA with a direct or indirect experience of cancer were interviewed between March 2006 and September 2007. Interviews were audio-recorded, transcribed verbatim and coded independently by two researchers. NVivo7 software was used to assist data management and analysis. A social constructionist framework provided a theoretical basis for analysis. Interpretation occurred within the research team with member checking and the involvement of an Aboriginal Reference Group assisting with ensuring validity and reliability.

Results: Outcomes indicated that misunderstanding, fear of death, fatalism, shame, preference for traditional healing, beliefs such as cancer is contagious and other spiritual issues affected their decisions around accessing services. These findings provide important information for health providers who are involved in cancer-related service delivery.

Conclusion: These underlying beliefs must be specifically addressed to develop appropriate educational, screening and treatment approaches including models of care and support that facilitate better engagement of Indigenous people. Models of care and support that are more culturally-friendly, where health professionals take account of both Indigenous and Western beliefs about health and the relationship between these, and which engage and include Indigenous people need to be developed. Cultural security, removing system barriers and technical/scientific excellence are all important to ensure Indigenous people utilise healthcare to realise the benefits of modern cancer treatments.
\end{abstract}




\section{Background}

A series of reviews recently highlighted differences in the epidemiology and the poorer outcomes of cancer in Indigenous people in Africa, Polynesia and Australia [1-4]. Given the complexity, expense and technology involved in modern cancer treatment, such disparities in cancer outcomes are unsurprising in the developing world. However, in Australia and New Zealand, the differences in cancer survival for Indigenous compared to the nonIndigenous populations warrants further investigation as these countries have well developed health systems offering universal healthcare for their citizens. Aboriginal and Torres Strait Islanders are the original inhabitants of Australia, and often referred to as Indigenous Australians. In this paper, the term Indigenous has been used to refer to first nation or the original inhabitants prior to colonisation in different countries including Australia. However, Aboriginal is the term preferred by vast majority Indigenous people of WA and is used for study participants.

Indigenous Australians have a lower incidence of cancer overall than the non-Indigenous population[3,5] although the epidemiology differs and includes higher rates of cancers with a poor prognosis. The improvement of around 20\% in cancer survival in Australia over the last twenty years[6] has not been shared by Indigenous survival figures, with Indigenous Australians 2.5 times more likely to die within five years of cancer diagnosis[7]. The factors underlying these poorer outcomes include health and social disadvantage, health risk behaviours, lower participation in screening programs, later diagnosis of cancer, lower uptake and poorer compliance with treatment and poorer continuity of care[3,8-11]. While the relationship between knowledge, attitudes, beliefs and behaviours is complex, most theories of behaviour acknowledge that beliefs and attitudes have also an important influence upon an individual's decision to access healthcare.

Health, health practices and care-seeking behaviour are culturally bound[12]. Culture is enmeshed in historical, social, economic and political relationships and processes[13] and influences the ways that people understand cancer which, in turn, affects their decision-making around care-seeking and accessing of services [14-18]. Beliefs such as 'talking about something can cause it to happen',[18] screening is unnecessary in the absence of symptoms; relating cancer with black magic; and religious beliefs about destiny have been found to impede early detection and treatment $[12,19,20]$.

The system of health care provision often fails to meet the needs of vulnerable groups. In Australia, Indigenous people are particularly at risk because, on a range of health and social indicators, they are the most marginalised of any identifiable group. While individual disadvantage is not unique to Indigenous people, it is the coalescence of markers of disadvantage and the resulting health outcomes that make understanding Indigenous beliefs particularly important. Cunningham et al recommended that messages from qualitative studies exploring the views and understanding Indigenous people with cancer must be taken into account[3].

Considerable differences exist in the perception and definition of health, healthy living, wellbeing, illness, and the meaning of disease and death between Indigenous Australians and the dominant Anglo-Australian society [2123]. Few attempts have been made to systematically explore Indigenous views about cancer[24]. This paper reports the first comprehensive Australian study of Aboriginal beliefs about cancer.

\section{Methods}

\section{Ethics approval}

The research adhered to guidelines for ethical conduct of Aboriginal and Torres Strait Islander health research[25], and was approved by the Human Research Ethics Committee (HREC) of Curtin University, the Western Australian Aboriginal Health Information and Ethics Committee, and the ethics committees of the Royal Perth and Sir Charles Gairdner Hospitals. Approval was also obtained from local Aboriginal Health Services. Efforts were made throughout to conduct the study in ways that would build capacity and help equalize power between Aboriginal participants and researchers[26,27]. An Aboriginal Reference Group (ARG) provided input throughout.

\section{Data collection}

This was a qualitative study in which the 'meaning of cancer' was explored among Aboriginal people in WA. Participants were Aboriginal males and females who were cancer patients/survivors $(\mathrm{n}=14)$, family members of people with or who had died from cancer $(n=16)$ and health service providers $(n=7)$ (Table 1). All spoke English and in-depth interviews between March 2006 and September 2007 explored participants' beliefs and how they felt about and made sense of cancer. A semi-structured interview schedule guided the interviews, with participants encouraged to introduce topics of importance to them. Data collection continued until there was repetition of themes.

\section{Data analysis}

The social constructionist framework which emphasizes the complex development and interaction between knowledge, meaning, interpretation and power in the constitution of belief systems[28] assisted understanding 
Table I: Characteristics of study participants

\begin{tabular}{ll}
\hline \multicolumn{1}{c}{ Aboriginal Participants $(\mathbf{n}=\mathbf{3 7})$} \\
\hline \begin{tabular}{l}
\multicolumn{1}{c}{ Area of Residence } \\
Urban participants \\
Regional participants
\end{tabular} \\
\hline Category of Respondent & 15 \\
Patients & \\
Family Members & 14 \\
Health Service Providers & 16 \\
\hline Sex & 07 \\
Male & \\
Female & 8 \\
\hline Age (years) & 29 \\
$30-39$ & \\
$40-49$ & \\
$50-59$ & 19 \\
$60+$ & 9 \\
\hline
\end{tabular}

in how the cultural meaning of cancer impacted upon participants' care-seeking behaviour. Social constructionists hold assumptions that individuals develop subjective meanings of their experiences that are guided, to some extent, by their beliefs and understanding which are constructed and negotiated socially and historically[29].

QSR NVivo7 software was used to manage data and support analysis. Thematic analysis of participants' transcribed interviews involved open coding independently by two researchers. Participants' responses were broken down into distinct units of meaning, or codes. Member checking was used to clarify whether emerging themes were an accurate reflection of the participants' experiences. The axial coding stage involved continuous comparisons of codes with one another to discover links between the categories[30], with related categories combined and compared to new data, arranged and rearranged to identify the key themes. To maximize reflexivity and rigour, all stages were discussed within the research team for verification and clarification of emerging themes[31]. Interpretation was assisted by consultation with ARG members and through presentations and feedback at various Aboriginal group meetings.

\section{Findings}

A range of beliefs were reported, some by most participants while others occurred less commonly. Beliefs foreign to the western scientific paradigm were just as likely to be expressed by urban and educated residents, including those who had worked within mainstream health settings. In reporting, emphasis is given to findings at odds with western medicine or experiences common to many participants.

\section{Perspectives and understanding of cancer Spirituality and cancer}

Some participants associated cancer with the spiritual world of curses, a form of punishment resulting from some misdeed the person had done in the past. Blaming others or a particular life experience as a cause of sickness is widespread within Aboriginal communities where spirituality exerts a powerful influence upon the notion of wellbeing[32,33]. Such attribution of cancer to spiritual causes can lead to fatalism, acceptance of the disease without question and not seeking help for it - "Aboriginal people have this notion of being sung... it's basically a bad magic put on somebody. " As a consequence of such beliefs, people may feel ashamed about their "wrong-doing" and hide their symptoms from others, delaying diagnosis or not pursuing treatment [6]. As stated by one family member:

"...it was almost like you deserved it or there was definitely this sense of shame. It was whispered. If someone died of a heart attack you would say that, but... all this cancer stuff was a whispered sort of stuff."

Relating cancer to spiritual causes is a pre-Enlightenment phenomenon and continues in Indigenous people elsewhere[19,34] and in other cultures[18,35]. It can often work as a coping mechanism to help overcome loss. One participant who had trained as a nurse in telling the story of her daughter's death from cancer talked of her daughter embodying her grandmother's spirit, being sent to explore her grandmother's country and ancestors. The daughter's death was accepted as inevitable, an outcome whispered to her by her mother's spirit long before her daughter's death.

\section{Fatalism and cancer as a death sentence}

Participants expressed deep fear and fatalistic expectations about cancer: 'cancer equals death'. This belief was considered as a major factor explaining why people ignore early symptoms and do not access treatment even after medical diagnosis.

"... they are just scared, because at the very end they know they are going to die. As soon as they hear the word cancer they are scared. Cancer is a scary word in the Aboriginal communities."

Fear of cancer is universal, yet attitudes have changed in most developed countries where messages emphasizing early detection and cure are publicised. Traditional attitudes towards cancer involving hopelessness and death have been replaced by a culture of hope [16], and the belief that cancer is incurable has been largely overcome[36]. However, the pessimistic attitudes towards cancer in this study reinforce similar findings in other Indigenous peoples $[19,34,37]$, with their unfortunate 
life-threatening consequences [19]. Participants considered that Indigenous interpretations of cancer as a 'death sentence' reflected the outcomes they have seen.

"It's sort of like your world crumbles. All we know about cancer is you die from cancer, not so much that cancer can be cured. You always know that as soon as you get cancer you are gone..., you are a goner".

Few members of their families and communities were seen to survive cancer:

"I saw my Mum goes through chemo and radiation... I saw my baby brother go through it. I seen my first cousin goes through it, and all my aunties all had cancer, all my mum's sisters. They have all passed away with cancer...."

Spirituality, fatalism and religion all co-existed. Eight participants said that contracting cancer was beyond the control of an individual, many believing that one was chosen by God to get it.

"I don't think that it's something you can prevent, it's just people are chosen. ... you can go and have tests every six months, and one day you could just have it and it's been there the whole time..."

Many cultures hold similar beliefs regarding destiny and God's will[18]. Such fatalistic beliefs are strongly associated with delays accessing pap smears and follow-up of abnormalities[17]. Patients with a fatalistic outlook are less likely to take steps to lower their cancer risk[38], and accept their "imminent demise and refuse potentially lifesaving treatment"[16].

Passivity existed alongside fatalism, expressed as belief that nothing could prevent a person from getting cancer: "When your time's up, your time is up, and you cannot do anything about it". One participant emphasized latent internal causes - 'everybody has got cancer cells in their body, but it just takes something to spark it off'. The participant was not referring to spontaneous cell abnormalities escaping normal immune surveillance[39] but rather elaborated on "something" as anything starting from curse, bad spirit, stress and bad luck, very different from the attribution in scientific explanations. Furthermore, such views do not acknowledge health behaviors as known risk factors for cancer[2]. Some participants voiced not wanting to worry about any sickness until they faced it, wanting to continue to live the way they had despite awareness of the associated risks:

"...you shouldn't stop your life because of all these sicknesses... that's just something that happens, and you deal with it when it comes along... so until then ... just forgetting... laughing...".

\section{Unrealistic expectations of treatment}

Contradicting the view 'cancer means death' were comments that Indigenous people accessing cancer treatments often put too much faith in doctors, believing they could fix their health problem. One respondent referred to "the doctors as gods ...they are the ones that are going to fix it, the miracle-makers". This confidence existed without understanding the complexities of cancer staging, co-morbid physical conditions, treatment options and the prognosis of different types of cancer. After finishing treatment, some thought they had been cured, that the cancer had gone and they could get on with their life normally, perhaps not attending for follow-up check-ups. One cancer patient spoke about her mother who believed she was cured by a mastectomy:

"she keeps saying, 'I have no more cancer... oh they took it all now... ' And I keep saying to her, 'Mum, no, it's not true. It's still in your body. Although they took your bubies off, you still got the disease. You got to be careful...."

Both cancer deaths and recurrences led to disappointment, often considered as an over-reliance or misplaced trust in doctors and western medicine. This could strengthen the distrust Indigenous people commonly feel towards western organisations including doctors and the medical system $[40,41]$. Personal stories of an individual's disillusionment with the medical system spread in the community, in turn influencing the choices others make around screening, early presentation and treatment for cancer. Distrust and negative experiences in the health system have similarly adversely impacted cancer care-seeking of other minorities[42].

\section{Cancer is contagious}

While not universal, some Aboriginal people believe cancer is contagious. Participants spoke about feeling isolated after diagnosis by the distancing behavior of some friends, family members and others who believed they were at risk of catching the cancer.

"There was a couple who were really scared of but there was one lady... she actually couldn't sit next to me. She sat across the room from me. She wouldn't talk to me for a long time, because she was scared...

Other studies have shown strong links between a person's beliefs about contagiousness, hiding their sickness and avoiding treatment, and feeling stigmatized or fearing being ostracized $[19,29]$. Although the belief that cancer is contagious is almost non-existent among the general pop- 
ulation in WA[36], it can persist among some people from diverse cultural backgrounds[43].

\section{Understanding of cancer}

Fatalistic beliefs and attitudes in the general population have changed as a result of scientific research, dissemination of information and education to help people understand the biological basis of cancer and modern treatment. However, the poorer educational background and socio-economic conditions of many Indigenous Australians have limited their access to information and understanding about disease. A lack of knowledge about types of cancer, symptoms, treatment options and outcomes was apparent, with some respondents having never considered what type of cancer a loved one had. Irrespective of geographic residency, respondents reported not initially recognising the cancer symptoms and delaying getting them checked. One woman had never taken the time to find out about serious illnesses and "didn't have a clue that it was the start of ... where that brown part puckering up, tightens up." The idea of self examination, of checking yourself for abnormalities that appeared to be foreign: "He asked how long I had the lumps (under my arms and neck)...I asked what lumps, I hadn't even felt any lump."

Attribution of cause for cancer was often unsophisticated:

"She thought her nose was bleeding because her husband punched her in the nose, and I don't know that she ever understood that it was anything more than that, because that was her experience was, everything was all right until he punched her in the nose and it started bleeding. "

Close family members were often unsure about what was happening to relatives and felt they could have helped more had they been better informed or more knowledgeable. Comments such as "we didn't know what was happening" and "We didn't know that she got cancer until she died" were common. These comments reflect communication problems for Aboriginal people within health facilities, and ignorance about cancer symptoms such as weight loss, anorexia and bleeding. "I didn't relate dad's condition to cancer. I found out later when I read up about it ...it was... almost ten years after I lost my dad."

Working in health services had improved some participants' understanding and knowledge about cancer but they commented on the lack of understanding in the Indigenous community: "a lot of Indigenous people...I suppose 70 to 80 per cent, wouldn't really know properly." Another commented:

"I don't think they understand it. They don't understand about prevention. They don't understand about early detec- tion and screening. Really, I felt that - from working there - some of their experiences or their understanding is so simple, it is very childlike."

Poor knowledge about cancer warning signs, screening and risk factors among minority populations have been reported elsewhere[17,44,45]. This limited understanding contributes to the many communication gaps between practitioners and patients, increasing patients' frustration with doctors and the medical system.

\section{Perceptions of cancer screening}

Understanding of cancer screening, its purpose and importance was often limited and vague. Ambivalence about participation in screening is unsurprising, particularly if there is a fatalistic view of cancer. As one health worker commented, "It's a sense that why I am doing a pap smear is to tell them they have got cancer and they are going to die from it...." Some participants believed that accessing screening would prevent cancers from occurring, with a few viewing screening as an early diagnostic tool. The discomfort and inconvenience of screening, "fear of knowing", "fear of having their breast squashed" and the "shame" of being touched by another person, were relayed as factors why Aboriginal women do not participate in screening programs. One woman referred to the shame of letting another woman touch her breasts or private parts and concern of being stigmatized as "lesbian". Prohibitions were also in place for men.

"The prostate thing with the Aboriginal men is... like I say is a 'taboo'... area. They will not go and get a simple test done by the doctor... they feel very funny about it, and so they usually leave it until the last minute, and sometimes that's just too late."

\section{Urban versus rural/remote differences}

The research explicitly proposed to examine differences in beliefs and understandings of regional compared to urban Aboriginal people who were considered likely to have more acculturation to western understandings. However, the range of views and beliefs did not map readily on the basis of geography or residence. Aboriginal people are mobile and many participants maintain connection with their homeland and culture despite living elsewhere $[32,46]$. One participant commented about returning to her country:

"I just feel replenished. My soul is just ... sort of filled up again. I'm home; 'This is where I feel so good. ' And it feels good in here. I might not feel healthy. I might have a cold or whatever, but inside I feel ...It just fills me up. It's like a warm bath inside..." 


\section{Bush medicine and traditional Aboriginal healing practices}

Other than a few participants "never brought up that traditional way", use of bush medicines for cancer was widely reported. The Indigenous "holistic view" of life $[47,48]$ in which health is defined as their total wellbeing [49] was frequently iterated: "Healing is not just physical; it's mental, emotional and spiritual as well. " For Indigenous people, "a positive outlook and in-look" was considered necessary to be healthy: "If you feel good inside regardless of your health, it will help you in any medical problems". The majority of cancer patients had used bush medicine either sequentially or concurrently[50] with Western medicines.

"There is something in it...that is good for your insides, just as a cleanser. Makes all your body organs healthy and strong, it gets rid of all your internal stress. "

Participants also emphasized the importance of cancer being diagnosed at an early stage for bush medicine to work. Even when cure was not possible, bush medicine was used for palliation, often signifying a re-connection to land, ancestral and spiritual roots that enhanced the person's overall wellbeing.

Use of complementary and alternative medicine is high among cancer patients[51,52]. Certain populations, including Indigenous people worldwide, have their own approaches to healing as part of their culture $[50,53]$. Western health practitioners need to understand and acknowledge traditional healing and treatment approaches in order to work and communicate effectively with Indigenous patients.

\section{Discussion}

Patients' beliefs influence their care-seeking behaviour for cancer-related services. Considerable literature shows that Indigenous people are often unwilling to use mainstream health services[32], and cancer services are no exception, with lower Indigenous uptake and compliance with cancer treatments. To increase Indigenous people's willingness to accept modern oncology treatments will require a different approach to engaging them in treatment, one which understands and addresses their concerns and provides more psychosocial and holistic care alongside Western medical treatment. Yet to date, understanding Indigenous psycho-social and cultural beliefs and fears about cancer and their impact on care-seeking has been largely neglected despite qualitative methodology being useful for health services research in multicultural settings[54]. The findings from this study align with the social constructionist approach [55], which considers how culture, social life, social interactions and relations shape people's beliefs and understanding about cancer which in turn influences their cancer care-seeking behaviour. This relationship is illustrated in Figure 1.

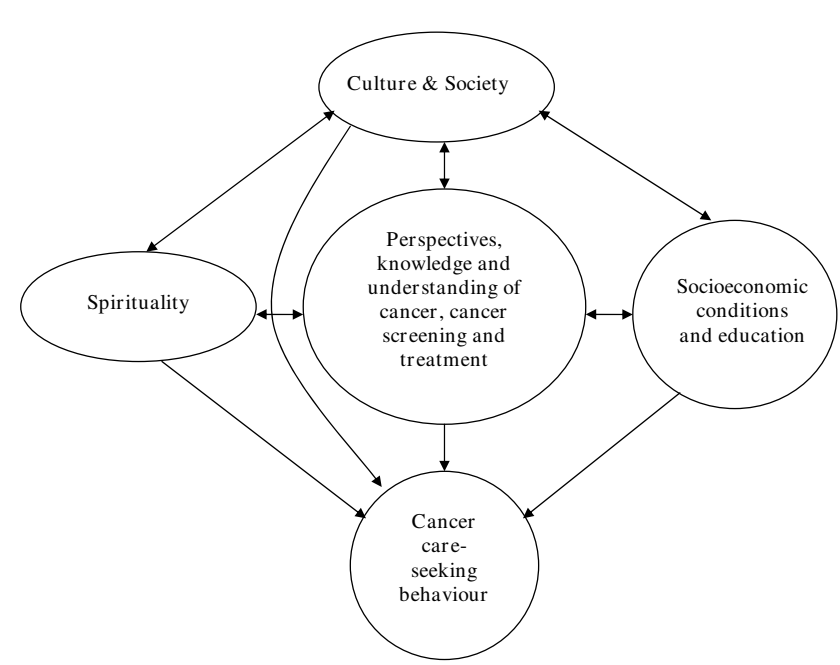

Figure I

Meaning-making around cancer and its impact on care-seeking behaviour.

Beliefs, understanding and interpretation stem from shared values, social relations within and between the family and the community, past experiences, cultural identity, and values[56,57]. Like many other cultures[18,58], notions of 'living well', 'sickness' or 'illness' present a complex, dynamic picture in Indigenous populations. Concept of health and wellbeing range from 'absence of symptoms of illness' to a more complex and holistic view of health as the consequence of physical, environmental, mental, and spiritual balance. Lifestyle factors, a person's social relationship with others and harmony with their culture are considered interrelated influences on health[59]. Thus, there is poor compatibility between the underlying principles of the Western reductionist medical system and traditional Indigenous health beliefs $[50,59]$, or even those more recently socially constructed, which shape their care-seeking and willingness to engage with services. Changing community narratives by respecting Aboriginal culture, through education and improving life circumstances and trust of the health system will be important to change the constructs within which cancer beliefs are framed. Health care providers must consider, respect and respond to these needs if they are truly committed to improving Indigenous health outcomes.

The overall pessimistic attitude of Aboriginal people towards cancer as a 'killer' resonates with that of many other cultures $[60,61]$. Participants' understanding that cancer can often be delayed or overcome with timely Western medical treatment was limited. They had limited access to relevant information, and the shame attributed to cancer and reluctance to talk about it meant stories of 
- Recognise cultural diversity and that not everyone has a strong understanding of the biological processes underpinning disease; some cultures have more traditional understandings of causation that are based in tradition and superstition

- Understand and consider that an Aboriginal patient might have different perspectives towards disease and treatment than a Western-trained doctor, and respect their right to participate in their own care

- Respect Aboriginal people and culture and show concern for the wellbeing of Aboriginal clients by seeking out and participating in cultural safety training and acting upon it Encourage other colleagues and service staff to do the same

- Practice person-centered care. Improve continuity of care and avoid the busyness and business in bed management in ways talk to the patient and close family members to assess their knowledge and understanding about cancer and make comprehensible suggestions

- Ensure Aboriginal patients' wishes to include their family in discussions are recognised. Address patients and accompanying family members' concerns and misunderstandings with regard to cancer

- Ensure Aboriginal health staff are included in the treatment team wheneve possible. Communicate with the Aboriginal patients in plain language

- Broach patients' use of alternative and traditional medicine usage and show respect towards patients' use of complementary and alternative medicines

- Explain to the Aboriginal patients and family members about the possible outcomes and chances from treatment alternatives and help them taking an informed decision

- Show respect to Aboriginal patients and their family members involving them in decision making regarding treatment initiation and continuation

- Ensure there are available information materials on cancer which are easy-tounderstand, culturally appropriate and available for use with Aboriginal people

\section{Figure 2}

\section{Lessons for health practitioners.}

survival were not widely disseminated. Appropriately targeted education campaigns, Aboriginal cancer support services and opportunities for Aboriginal survivors of cancer to be advocates in their communities are needed.

Traditional beliefs are not simply displaced by western biomedical understanding, they can co-exist. A study of Indigenous Australian and Papua New Guinean health science students showed that the Indigenous university students conceptualized health and illness in a way which accommodated biomedical science within an integrated scheme of mental, physical and spiritual well-being[59]. Education in western health care did not alter their core philosophy towards life and their spiritual belief system. Therefore, ensuring services are culturally appropriate is important for all Indigenous people, including those with higher levels of education and living in urban areas.

Many Aboriginal people retain a preference for using bush medicine and traditional healing, even for a "western" disease like cancer. The "doctor-dependent, hospital-based, curative western health care model"[58] for treating cancer does not generally recognize, and incorporate traditional systems for healing. However, the combined use of both types of expertise can optimise the response to various health problems, including cancer.
Participants argued for cross-cultural educational initiatives where western cancer support entails an understanding, acknowledgement and acceptance of Aboriginal belief systems and that they are different to western understandings. Aboriginal people also need to understand that western understandings are different. Consideration of cultural differences is essential for health care providers to fully appreciate the impact of this disease on patients' physical and mental well-being. Mutually appreciative understanding of cultural differences is a key to encouraging Indigenous people's willingness to participate in health care to enhance early detection, develop appropriate interventions and ultimately improve cancer outcomes[62].

Paramount to cancer being curable is diagnosis at a stage before spread, when treatments are most effective. The association of cancer with death reflects the tragic reality that Indigenous people are often diagnosed with cancer at an advanced stage, and consequently die within a short period of diagnosis $[5,63,64]$. Participants commented that some people who develop symptoms consistent with cancer avoid assessment and diagnosis, preferring to hide their symptoms, again a phenomenon not restricted to Aboriginal people[65]. In this way, they avoid confronting their diagnosis and potential mortality for a period of time. This situation needs to be approached through effective education about risks, symptoms and treatments for cancer. In addition, reducing barriers in access, providing more culturally secure health service provision, increasing the visibility of Aboriginal cancer survivorship and focusing attention on the importance of early diagnosis are strategies that can enhance cancer mortality in Indigenous communities.

The study was undertaken only in Western Australia, and it may not reflect the views of Aboriginal people throughout Australia who have different cultural traditions and beliefs. Men were under-represented in our participants which may be due to the primary interviewer being female, the predominance of women among the ARG members and in the community-based health workforce, and the higher utilisation of health services by women compared to men[66,67]. Another limitation was that participants needed to be able to speak English, and this proficiency in English would undoubtedly have some affects on acculturation and exposure to western understandings of health and illness.

\section{Conclusion}

Beliefs are important but are only one influence on health behaviour. The concept of cultural safety requires a change in emphasis, away from the failings of individual patients (to attend, to comply etc) to critical examination of system factors in health care delivery that may interfere 
with an individuals' or a collectivity's willingness to attend a health service or take up treatments that are available. In addition to clinicians needing an understanding of cultural beliefs, a focus on the practice, skills and behaviour of the health system is required so that it appropriately responds to barriers and incorporates "culture" into service delivery'[68]. Models of care and support that are more culturally-friendly, where health professionals take account of both Indigenous and Western beliefs about health and the relationship between these, and which engage and include Indigenous people need to be developed[69]. Key lessons for health practitioners are summarised in Figure 2. Only by combining cultural security with technical/scientific excellence and removing system barriers will the potential benefits of modern treatments be realised through increased willingness and ability of Indigenous people to access and participate in healthcare.

\section{Competing interests}

The authors declare that they have no competing interests.

\section{Authors' contributions}

SS participated in the project's design, carried out the data collection and analysis for this project, prepared the initial draft. LF was involved in the data analysis phase and writing. DB helped interpret findings, and commented upon drafts of the manuscript. SCT coordinated the whole project, participated in the design and assisted with the conduct of the study and writing. All authors read and approved the final manuscript.

\section{Acknowledgements}

This research was originally supported by a grant from The Cancer Council of Western Australia. Shaouli Shahid is currently supported by Curtin University and the NHMRC Capacity Building Grant (ID 457279). We thank all of the participants for sharing their stories and experiences and the many health service providers that assisted the process. We acknowledge the invaluable contribution of the Aboriginal Reference Group and other investigators and colleagues for their advice: Peter Howat, Brian Bishop, Timothy Threlfall, Katie Thomas, Moyez Jiwa, John Mallard, Terry Slevin, Leanne Pilkington, Francine Eades, Dot Henry, Gwen Rakabula, Jude Comfort and Kim Worthington.

\section{References}

I. Parkin DM, Sitas F, Chirenje M, Stein L, Abratt R, Wabinga H: Part I: Cancer in Indigenous Africans-burden, distribution, and trends. Lancet Oncol 2008, 9:683-692.

2. Dachs GU, Currie MJ, McKenzie F, Jeffreys M, Cox B, Foliaki S, Le Marchand L, Robinson BA: Cancer disparities in Indigenous Polynesian populations: Maori, Native Hawaiians, and Pacific people. Lancet Oncol 2008, 9:473-484.

3. Cunningham J, Rumbold AR, Zhang X, Condon JR: Incidence, aetiology, and outcomes of cancer in Indigenous peoples in Australia. Lancet Oncol 2008, 9:585-595.

4. Sitas F, Parkin DM, Chirenje M, Stein L, Abratt R, Wabinga H: Part II: Cancer in Indigenous Africans-causes and control. Lancet Oncol 2008, 9:786-795.

5. Valery PC, Coory M, Stirling J, Green AC: Cancer diagnosis, treatment, and survival in Indigenous and non-Indigenous Australians: a matched cohort study. Lancet 2006, 367:1842-1848.
6. Lowenthal RM, Grogan PB, Kerrins ET: Reducing the impact of cancer in Indigenous communities: ways forward. Med J Aust 2005, 182:105-106.

7. Condon JR, Barnes T, Armstrong BK, Selva-Nayagam S, Elwood JM: Stage at diagnosis and cancer survival for Indigenous Australians in the Northern Territory. Med J Aust 2005, 182:277-280.

8. Australian Institute of Health and Welfare: Australia's health 2006: The tenth biennial health report of the Australian Institute of Health and Welfare. Canberra: AlHW; 2006.

9. Binns PL, Condon JR: Participation in cervical screening by Indigenous women in the Northern Territory: A longitudinal study. Med J Aust 2006, I 85:490-494.

10. Coory MD, Fagan PS, Muller JM, Dunn NA: Participation in cervical cancer screening by women in rural and remote Aboriginal and Torres Strait Islander communities in Queensland. Med J Aust 2002, 177:544-547.

II. Eley JW, Hill HA, Chen VW, Austin DF, Wesley MN, Muss HB, Greenberg RS, Coates RJ, Correa P, Redmond CK, et al.: Racial differences in survival from breast cancer: Results of the National Cancer Institute Black/White survival study. JAMA 1994, 272:947-954.

12. Petersen S, Soucar B, Sherman-Slate E, Luna L: The social construction of beliefs about cancer: A critical discourse analysis of racial differences in the popular press. J Appl Biobehavioral Res 2004, 9:20I-229.

13. Anderson JM, Kirkham RS: Discourses on health: A critical perspective Waterloo, Canada: Wilfred Laurier University Press; 1999.

14. Nwoga IA: Traditional healers and perceptions of the causes and treatment of cancer. Cancer Nurs 1994, 17:470-478.

15. Lees S, Papadopoulos I: Cancer and men from minority ethnic groups: An exploration of the literature. Euro J Cancer Care 2000, 9:221-229.

16. Dein S: Explanatory models of and attitudes towards cancer in different cultures. Lancet Oncol 2004, 5: I 19-124.

17. Nelson K, Geiger AM, Mangione CM: Effect of health beliefs on delays in care for abnormal cervical cytology in a multiethnic population. J Gen Intern Med 2002, 17:709-716.

18. Yeo SS, Meiser B, Barlow-Stewart K, Goldstein D, Tucker K, Eisenbruch M: Understanding community beliefs of Chinese-Australians about cancer: Initial insight using an ethnographic approach. Psycho-Oncology 2005, | 14:174-186.

19. McGrath P, Holewa H, Ogilvie K, Rayner R, Patton MA: Insights on Aboriginal peoples' views of cancer in Australia. Contemp Nurse 2006, 22:24I-254.

20. Myers RE, Hyslop T, Wolf TA, Burgh D, Kunkel EJ, Oyesanmi OA, Chodak G]: African-American men and intention to adhere to recommended follow-up for an abnormal prostate cancer early detection examination result. Urology 2000, 55:716-720.

21. McGrath $\mathrm{P}$, Holewa $\mathrm{H}$ : Seven principles for Indigenous palliative care service delivery: Research findings from Australia. Austral-Asia Journal of Cancer 2006, 5: I79-186.

22. McMichael TA: National Aboriginal Health Strategy. Aboriginal Health Information Bulletin 1989, 12:12-14.

23. Weeramanthri T: Knowledge, language and mortality: Communicating health information in Aboriginal communities in the Northern Territory. Australian Journal of Primary Health 1996, 2:3-1I.

24. Shahid S, Thompson SC: An overview of cancer and beliefs about the disease in Indigenous people of Australia, Canada, New Zealand and the United States. Aust N Z J Public Health 2009, 33:109-118.

25. NHMRC: Values and ethics: guidelines for ethical conduct in Aboriginal and Torres Strait Islander health research. Canberra 2003.

26. Browne AJ, Fiske JA: First Nations women's encounters with mainstream health care services. West J Nurs Res 200I, 23:126- 147

27. Airhihenbuwa CO: Health and Culture: Beyond the Western Paradigm California: Sage Publications, Inc; 1995.

28. Berger PL, Luckmann T: The Social Construction of Reality: A Treatise in the Sociology of Knowledge New York: Anchor Books; 1966.

29. Creswell JW: Research Design: Qualitative, Quantitative and Mixed Methods Approaches 2nd edition. California: Sage publications, Inc; 2003.

30. Grbich C: Qualitative Research in Health: An Introduction Sydney: Allen \& Unwin; 1999. 
31. Kitto SC, Chesters J, Grbich C: Quality in qualitative research. Med J Aust 2008, 188:243-246.

32. Morgan DL, Slade MD, Morgan CM: Aboriginal philosophy and its impact on health care outcomes. Aust N Z J Public Health 1997, 21:597-601

33. Eckersley RM: Culture, spirituality, religion and health: Looking at the big picture. Med J Aust 2007, 186:s54-s56.

34. Burhansstipanov L: Cancer: a growing problem among American Indians and Alaska Natives. In Promises to Keep: Public health policy for American Indians and Alaska Natives in the 2 I st century Edited by: Dixon M, Roubideaux Y. Washington, DC: The American Public Health Association; 2001:223-252.

35. Kohli N, Dallal AK: Culture as a factor in the causal understanding of illness: a study of cancer patients. Psychology and Developing Societies 1998, 10:1 I5-129.

36. Donovan RJ, Carter OB, Jalleh G, Jones SC: Changes in beliefs about cancer in Western Australia, 1964-2001. Med J Aust 2004, I 81:23-25.

37. Prior D: Aboriginal women's perception of cancer. Aust Nurs J 2006, 1 3:27.

38. American Association for Cancer Research: Fatalistic beliefs about cancer cause many to ignore cancer prevention advice. AACR; 2007

39. Kim R, Emi M, Tanabe K: Cancer immunoediting from immune surveillance to immune escape. Immunol Cell Biol 2007, I 2 I: I- I4

40. Holmes W, Stewart P, Garrow A, Anderson I, Thorpe L: Researching Aboriginal health: experience from a study of urban young people's health and well-being. Soc Sci Med 2002 54:1267-1279.

4I. Shahid S, Finn L, Thompson SC: Barriers to participation of Aboriginal people in cancer care: communication in the hospital setting. MJA 2009, 190:574-579.

42. Jennings K: Getting black women to screen for cancer: Incorporating health beliefs into practice. J Am Acad Nurse Pract 1996, 8:53-59.

43. Wong-Kim E, Sun A, DeMattos MC: Assessing cancer beliefs in a Chinese immigrant community. Cancer Control 2003, 10:22-28.

44. Shokar NK, Vernon SW, Weller SC: Cancer and colorectal cancer: knowledge, beliefs and screening preferences of a diverse patient population. Fam Med 2005, 37:34I-347.

45. Armstrong N, Murphy E: Weaving meaning? An exploration of the interplay between lay and professional understandings of cervical cancer risk. Soc Sci Med 2008, 67: 1074-1082.

46. Bessarab DC: A study into the meanings of gender by Aboriginal people living in urban (Perth) and regional (Broome) settings. In PhD thesis Curtin University of Technology, Department of Social Work and Social policy; 2006.

47. Aboriginal Cancer Care Unit: Analysis of the findings: Aboriginal cancer care needs assessment, "It's our responsibility". In August, 2005 Volume I. Toronto: ACCU, Cancer Care Ontario; 2002.

48. Ministry of Health NZ: Access to cancer services for Maori. Wellington School of Medicine and Health Sciences 2005.

49. Prilleltensky I: Promoting well-being: time for a paradigm shift in health and human services. Scandinavian J Public Health 2005 , 33:53-60.

50. Maher P: A review of 'traditional' Aboriginal health beliefs. Australian Journal of Rural Health 1999, 7:229-236.

51. Patterson RE, Neuhouser ML, Hedderson MM, Schwartz SM, Standish LJ, Bowen DJ, Marshall LM: Types of alternative medicine used by patients with breast, colon, or prostate cancer: Predictors, motives, and costs. J Altern Complement Med 2002, 8:477-485.

52. Richardson MA, Sanders T, Palmer JL, Greisinger A, Singletary SE: Complementary/alternative medicine use in a comprehensive cancer center and the implications for oncology. J Clin Oncol 2000, 18:2505-25I4.

53. Struthers R, Eschiti VS: The experience of indigenous traditional healing and cancer. Integrative Cancer Therapies 2004, 3:13-23.

54. Denzin NK, Lincoln YS: The Sage Handbook of Qualitative Research California: Sage Publications, Inc; 2005.

55. Burr V: An Introduction to Social Constructionism London and New York: Routledge; 1995.

56. Adelson $\mathrm{N}$ : Health beliefs and the politics of Cree well-being. Health (N Y) 1998, 2:5-22.
57. Arnold OF, Bruce A: Nursing practice with Aboriginal communities: Expanding worldviews. Nurs Sci Q 2005, 18:259-263.

58. Bhasin V: Medical Anthropology: A review. Ethno-Medicine 2007, I:I-20.

59. Boulton-Lewis G, Pillay H, Wilss L, Lewis D: Conceptions of health and illness held by Australian Aboriginal, Torres Strait Islander, and Papua New Guinea health science students. Australian Journal of Primary Health 2002, 8:9-16.

60. Borland R, Donaghue N, Hill D: Illness that Australians most feared in 1986 and 1993. Aust J Public Health 1994, 18:366-369.

61. Seffrin JR, Wilson JL, Black BL: Patient perceptions. Cancer 1991, 67:1783-1787.

62. Blackwell N: Cultural issues in Indigenous Australian peoples. In Oxford Textbook of Palliative Care 2nd edition. Edited by: Doyle D, Hanks G, McDonald N. Oxford: Oxford University Press; 1998:799-804

63. Dennis TD: Cancer stage at diagnosis, treatment, and survival among American Indians and non-American Indians in Montana. Cancer 2000, 89: $181-186$.

64. Haynes R, Pearce J, Barnett R: Cancer survival in New Zealand: Ethnic, social and geographical inequalities. Soc Sci Med 2008, 67:928-937.

65. Andersen BL, Cacioppo JT: Delay in seeking a cancer diagnosis: delay stages and psychophysiological comparison processes. Brit J Social Psychol 1995, 34:33-52.

66. Courtenay WH: Constructions of masculinity and their influence on men's well-being: A theory of gender and health. Soc Sci Med 2000, 50:1385-140I.

67. Bertakis KD, Azari R, Helms LJ, Callahan EJ, Robbins JA: Gender differences in the utilisation of health care services. J Fam Pract 2000, 49:147-152.

68. Thomson N: Cultural respect and related concepts: a brief summary of the literature. Australian Indigenous HealthBulletin 2005, 5: I-II.

69. Colomeda LA, Wenzel ER: Medicine keepers: Issue in indigenous health. Critical Public Health 2000, 10:243-256.

\section{Pre-publication history}

The pre-publication history for this paper can be accessed here:

http://www.biomedcentral.com/1472-6963/9/132/pre pub

Publish with Bio Med Central and every scientist can read your work free of charge

"BioMed Central will be the most significant development for disseminating the results of biomedical research in our lifetime. "

Sir Paul Nurse, Cancer Research UK

Your research papers will be:

- available free of charge to the entire biomedical community

- peer reviewed and published immediately upon acceptance

- cited in PubMed and archived on PubMed Central

- yours - you keep the copyright 